\title{
ENSINO DE ENFERMAGEM EM PORTUGAL: CONTRIBUTOS PARAA SUA HISTÓRIA
}

\author{
Felismina Rosa Parreira Mendes ${ }^{1}$, Maria de Fátima Mantovani ${ }^{2}$
}

\begin{abstract}
RESUMO: Trata-se de uma reflexão sobre o ensino de Enfermagem em Portugal. O objetivo foi identificar os marcos históricos centrais da evolução do ensino de Enfermagem em Portugal até finais do século XX. A enfermagem neste país nasceu sob o domínio da profissão médica e atrelada a hospitais, onde sempre esteve atrelada. Durante a maior parte do século 20, foi encarada como profissão de abnegadas e submissas a desempenhar tarefas auxiliares do médico e com formação em nível de ensino básico. Com a Revolução dos Cravos, em 1974, a profissão passou a ter três níveis, sendo exigida maior escolaridade para frequentar o curso, com vistas a preparar enfermeiros para participarem do planejamento do país. Com a criação da Ordem dos Enfermeiros, a enfermagem e o ensino ganharam estatuto e foram se autonomizando do poder médico. Um outro passo decisivo nessa direção foi dado em 1999 quando o ensino de enfermagem se tornou, definitivamente, de nível superior.
\end{abstract}

PALAVRAS-CHAVE: Ensino; História; Prática profissional; Enfermagem.

\section{NURSING TEACHING IN PORTUGAL: CONTRIBUTIONS TO ITS HISTORY}

ABSTRACT: This article focuses on nursing teaching in Portugal. The objective is to identify the landmarks in its evolution until the end of the 21th century. Nursing profession in Portugal was originally related to the medical activity and was mostly practiced in a hospital setting. During the most part of the 20th century, nursing was treated as an occupation of devoted and submissive women, with basic education, whose only role was to help doctors with patient care. After the Carnation Revolution, in 1974, the nursing profession was taught in three levels and students should have reached a higher education level to attend the nursing course, because these professionals should be prepared to participate in the country's planning. The creation of the Nursing Board conferred an autonomous status to this profession. Another decisive step toward nursing's independence was taken in 1999 when nursing began to be taught at a graduate level.

KEYWORDS: Teaching; History; Professional practice; Nursing.

\section{ENSEÑANZA DE ENFERMERÍA EN PORTUGAL: CONTRIBUCIONES PARASU HISTORIA}

RESUMEN: Se trata de una reflexión sobre la enseñanza de la Enfermería en Portugal. El objetivo fue identificar los marcos históricos centrales de la evolución de la enseñanza de la Enfermería en Portugal hasta finales del siglo XX. La enfermería en este país nació sobre el dominio de la profesión médica y vinculada a hospitales, donde siempre estuvo ligada. Durante la mayor parte del siglo 20, fue vista como profesión de abnegadas y sumisas, a desempeñar tareas auxiliares del médico y con graduación en nivel de enseñanza básica. Con la Revolución de los Claveles, en 1974, la profesión pasó a tener tres niveles, siendo exigida una formación más avanzada para frecuentar el curso, con el fin de preparar enfermeros para participar de la planificación del país. Con la creación de la Orden de los Enfermeros, la enfermería y la enseñanza ganaron estatuto y fueron adquiriendo autonomía del poder médico. Otro paso decisivo en esta dirección fue dado en 1999, cuando la enseñanza de la enfermería se volvió, definitivamente, de nivel superior.

PALABRAS CLAVE: Enseñanza; Historia; Práctica profesional; Enfermería.

${ }^{1}$ Enfermeira. Doutora em Sociologia. Professora Coordenadora da Universidade de Évora-UE-Portugal. Investigadora do Centro de Investigação de Estudos em Sociologia-CIES do Instituto Superior de Ciências do Trabalho-ISCTE e da Empresa de Lisboa. Colaboradora do Centro Investigação em Ciências e Tecnologias da Saúde-CICTS-UE.

${ }^{2}$ Enfermeira. Doutora em Enfermagem. Professora Adjunto da Universidade Federal do Paraná-UFPR. Membro do Grupo de Estudos Multiprofissional em Saúde do Adulto-GEMSA-UFPR. Pesquisadora Convidada do CICTS-UE.

Autor correspondente:

Felismina Rosa Parreira Mendes

Largo Senhor da Pobreza, s/n - 7000-811 - Évora-Portugal Recebido: 15/05/09

E-mail: fm@uevora.pt

Aprovado: 28/06/09

Cogitare Enferm 2009 Abr/Jun; 14(2):374-8 


\section{INTRODUÇÃO}

Ao final do século XIX, as pressões exercidas pelas descobertas científicas e as transformações políticas e sociais que puseram em causa o antigo sistema de saúde em Portugal abriram o debate da enfermagem laica versus religiosa.

A partir do avanço científico do século XIX tornou-se imperiosa a formação de enfermeiras com o domínio dos conhecimentos de princípios de higiene, submissas ao médico e à administração hospitalar, que conhecessem e respeitassem os limites das suas funções. Não bastasse a moral de devoção e abnegação, para a afirmação profissional, sua formação era deficiente e este era o aspecto que se destacava nas enfermeiras desta época ${ }^{(1)}$.

Foi neste contexto que surgiram os primeiros cursos destinados a preparar tecnicamente as enfermeiras para as novas necessidades resultantes das mudanças que se operavam nos hospitais, nas políticas de saúde e na medicina ${ }^{(2)}$. Surgiram nos hospitais das grandes cidades portuguesas (Lisboa, Porto e Coimbra) onde a enfermagem era laica, apesar de todas as tentativas para introdução de religiosas. Emboras as ordens religiosas tenham sido abolidas em 1834, a partir de 1850 muitas congregações se instalaram em Portugal com o fim de fundar escolas, hospitais e outras instituições de assistência, sobretudo no norte do país ${ }^{(3)}$.

No entanto, sempre que era posta em causa a competência, a capacidade de dedicação e abnegação das enfermeiras laicas, as associações e os sindicatos tomavam posição, refutando todas as acusações feitas pelos defensores da enfermagem religiosa e censurando o proselitismo religioso exercido junto dos doentes:

\begin{abstract}
A blusa branca deve representar para o doente uma blindagem que o ponha a coberto de tudo quanto não sejam os cuidados e funções [...] inerentes à enfermagem. A enfermagem não é católica, protestante ou israelita; é simples e unicamente enfermagem e só enfermagem [...] tudo quanto não seja assim é atentatório da dignidade e da liberdade e a enfermagem de cunho religioso é perniciosa e inconcebível nos tempos que correm ${ }^{(4: 23)}$.
\end{abstract}

No fundo, o que todas as associações profissionais da época contestavam era o exercício da enfermagem por indivíduos não habilitados e a defesa do emprego. Até o final do século XIX, percebese a filiação dupla da enfermagem: a religiosa (servir um ideal, seguir uma vocação) e a médico-técnica (capacidade de execução). De um lado o peso da herança de um modelo religioso e do outro a submissão à autoridade/modelo médico(5) .

A moderna enfermagem foi construída pelos médicos dos hospitais que sentiam necessidade de assistentes clinicamente melhor qualificadas ${ }^{(5)}$. Portanto, buscar aspectos na história do ensino da enfermagem portuguesa possibilita o descortinar da trajetória evolutiva da mesma e os caminhos percorridos para seu reconhecimento como uma profissão de nível superior. O objetivo deste artigo é identificar os marcos centrais da evolução do ensino de Enfermagem em Portugal até finais do século vinte.

\section{OS PRIMEIROS CURSOS DE ENFERMAGEM}

Em finais do século XIX, quase todo o pessoal admitido para servir os doentes era analfabeto e apenas alguns hospitais se preocupavam em dar-lhes, ocasionalmente, alguma formação empírica. A necessidade de formar trabalhadores de enfermagem foi sentida, sobretudo, nos hospitais das três maiores cidades, onde se ministrava o ensino oficial da medicina: Lisboa, Porto e Coimbra ${ }^{(2)}$.

Os primeiros cursos de enfermagem ${ }^{(6)}$ realizados em Portugal datam de 1881, 1886 e 1887 respectivamente, nos hospitais das cidades referidas. Nestes cursos era fornecida instrução prática e para tal foram elaborados manuais, com apontamentos das lições, os quais explicitavam as múltiplas atividades que as enfermeiras deviam dominar, como por exemplo:

[..]. levar ao banho, às costas, os doentes [...] para os lavar, levar todas as refeições às enfermarias, varrer e limpar estas e fazer as camas, vigiar enfermos [...] chamar o Vigário [...] amortalhar os cadáveres [...] despejar e limpar diariamente os tanques dos banhos [...] ter sempre limpos os urinóis e bacios, bem como os púcaros dos xaropes e purgas $[\ldots]^{(7: 99)}$.

No século XX (1901) foi fundada a Escola de Enfermagem com sede no Hospital de S. José como Escola Profissional de Enfermagem e passou a ministrar um Curso Básico com a duração de um ano e um Curso Completo com dois anos de duração que funcionava nas próprias instalações do hospital ${ }^{(7)}$. A partir daí, foram surgindo novas Escolas, muitas delas geridas por ordens religiosas ou fundações privadas, com formação centrada no domínio da prática, na primeira parte do Curso. A ênfase era dada para a destreza e perícia manuais e a enfermeira seria um misto de bondade, habilidade e obediência ${ }^{(4)}$.

A Escola de Enfermagem de S. Vicente de Paulo-Lisboa foi fundada por Eugénia Tourinho, em 
1937, religiosa brasileira, diplomada na França. O curso tinha três anos, com matérias de natureza humanística, como higiene mental, psicologia, sociologia entre outras e foi inovadora para a época ${ }^{(4,7)}$.

Três anos mais tarde e seguindo esta linha de inovação foi criada, pelo Ministério da Educação Nacional, a Escola Técnica de Enfermeiras do Instituto Português de Oncologia - Lisboa. Pretendia-se formar enfermeiras altamente qualificadas, capazes de participar, pela sua competência científica, técnica e humana, na melhoria da assistência de saúde. Com um curso de três anos e exigindo como habilitação mínima, o correspondente a nove anos de escolaridade, esta escola teve reconhecidamente um papel relevante na evolução do ensino de enfermagem em Portugal, sob orientação da Fundação Rockfeller ${ }^{(7-8)}$.

\section{A PRODUÇÃO LEGISLATIVA E A EVOLUÇÃO DO ENSINO DE ENFERMAGEM}

Foi já durante o Estado Novo que se procedeu à reforma do ensino e da prática de enfermagem ${ }^{(9)}$, com a publicação do Decreto-Lei n. 31913, de 12 de março de $1942^{(10)}$. Este impôs a proibição de casamento às enfermeiras, medida inspirada no modelo fascista italiano e que só seria revogada mais de vinte anos depois, em 1963.

Neste contexto, e durante a década de 40 , a enfermagem portuguesa era uma espécie de sacerdócio - de dedicação e sacrifício pela vida e saúde alheias - em que a ordem do dever estava sempre presente. Muitas vezes, a enfermagem, foi vista como um passo propedêutico para o futuro médico que devia fazer um estágio como enfermeiro no qual aprenderia a fazer uma cama, a vestir e despir um doente, a fazer um cataplasma, a preparar uma tisana (infusão), a pôr um vesicatório, sanguessugas e ventosas, a sangrar, a dar um clister e uma massagem. Em suma, aprender e mostrar que sabia o que era a prática e a virtude de um enfermeiro dócil e afável ${ }^{(4)}$.

Com a legislação de $1952^{(11)}$ seria finalmente organizado o ensino de enfermagem nas Escolas oficiais. O objetivo desta nova alteração legislativa era formar e preparar melhores profissionais para trabalharem em serviços hospitalares e de Saúde Pública. A partir daí, passaram a existir três cursos distintos: Curso de Enfermagem Geral com três anos de duração; Curso de Auxiliares com um ano e meio; Curso Complementar de Enfermagem e era exigida a escolaridade de 6 anos, 4 anos e 9 anos respectivamente.
O ensino passou a ser ministrado em Escolas de Enfermagem, oficiais ou particulares, às quais foi concedida autonomia técnica e administrativa. Os Monitores (enfermeiros Professores) passaram a ter uma preparação específica com a criação do Curso Complementar de Enfermagem (que na prática correspondia a uma pós-graduação em pedagogia ou gestão de enfermagem). O ensino passou a ser distribuído por aulas teóricas, aulas práticas e estágios com frequência obrigatória.

Entretanto, em 1965 houve uma reforma do ensino de enfermagem. Nesta reforma destacam-se os seguintes aspectos: exigência de 9 anos de escolaridade para a admissão ao Curso de Enfermagem Geral, formação mais equilibrada e a orientação das enfermeiras para diversas áreas de trabalho, com a ênfase na pedagogia participativa e ativa. Apelava-se a que os hospitais de "centros curativos" se convertessem em centros de educação das populações para a prevenção da doença e para a promoção da saúde e bem-estar social; recomendavase também que os exames passassem a centrar-se mais em aspectos da enfermagem, em detrimento de matérias do foro médico, possibilitando com isso o ganho de maior autonomia e especificidade, abrindo-se assim às influências internacionais (e nomeadamente às orientações da Organização Mundial de Saúde e do Conselho Internacional de Enfermeiros) ${ }^{(7)}$.

Tal como toda a sociedade portuguesa, também o ensino de enfermagem não passou incólume pelas transformações do 25 de Abril de 1974. A reforma seguinte do ensino de Enfermagem deu-se em 1976 e resultou de um trabalho conjunto de Escolas, Sindicato dos Enfermeiros Portugueses e Associação Portuguesa de Enfermeiros, que efetuaram a revisão curricular do Curso de Enfermagem ${ }^{(7)}$.

Em 1976 foi publicado o novo regulamento dos órgãos de gestão das escolas de enfermagem e só em 1979 passou a ser exigida como habilitação mínima para a admissão ao curso de enfermagem geral o correspondente ao atual $11^{\circ}$ ano de escolaridade. Uma das últimas alterações no ensino da enfermagem, foi a sua integração no Ensino Superior Politécnico-ESP, sob a dupla tutela do Ministério da Educação e do Ministério da Saúde, que ocorreu em $1988^{(7)}$.

A partir dessa data as escolas de enfermagem, transformadas em Escolas Superiores de Enfermagem, passaram a conferir os graus de Bacharel (Ensino Politécnico em Portugal) e de Estudos Superiores Especializados (em Enfermagem Comunitária, Saúde 
Materna e Obstetrícia, Saúde Infantil e Pediatria, Saúde Mental e Psiquiatria, Reabilitação e Médico-Cirúrgica). Cada uma organizou o seu próprio plano curricular ${ }^{(12)}$.

Com a integração no ESP, abriu-se às escolas de enfermagem a oportunidade de conquistar a vertente da autonomia que lhes faltava: a científica. Esta passou também pela valorização dos docentes e pelo desenvolvimento da investigação científica, ainda incipiente. No início dos anos 90 os docentes passaram a integrar a carreira do ESP sendo exigida formação acadêmica, obrigando-os a dar início a um processo de formação em mestrados e doutorados nas universidades portuguesas e estrangeiras. Esse movimento se mantém na atualidade ${ }^{(13)}$.

Em finais do século XX (1997), a criação da Ordem dos Enfermeiros ${ }^{(14)}$ veio contribuir decisivamente para o desenvolvimento da Enfermagem como prática profissional cada vez mais complexa e diferenciada. Vem afirmar como uma comunidade profissional e científica da maior relevância no funcionamento do sistema de saúde. Ainda, na garantia do acesso da população a cuidados de saúde de qualidade e, indiretamente, pressionar o ensino de enfermagem para dar resposta à formação, cada vez mais exigente, dos enfermeiros portugueses.

Em 1999 o Ministério da Ciência e Ensino Superior aprovou a criação do Curso de Licenciatura em Enfermagem, assim chamados os cursos de graduação superior no país, e dos Cursos de PósLicenciatura de Especialização em Enfermagem, antes denominados Cursos de Especialização em Enfermagem $^{(15)}$. Com esta alteração, muitas Escolas passaram a integrar os Institutos Politécnicos da sua área de inserção, outras às Universidades da respectiva área geográfica e outras ainda, sofreram processos de fusão, mantendo-se como Escolas Superiores não integradas - caso das escolas das três maiores cidades portuguesas (Lisboa, Porto e Coimbra).

\section{COMENTÁRIOS FINAIS}

O ensino da enfermagem em Portugal teve um percurso complicado, por vezes até conflituoso, não sendo fácil separá-lo da sua prática porque se interligam e influenciam mutuamente. Desde a criação do primeiro Curso e da primeira Escola de Enfermagem há mais de um século, até à sua integração no sistema educativo nacional, um longo caminho foi percorrido.

Iniciou com a necessidade de mão-de-obra barata, durante muitos anos o hospital foi o único local de formação das enfermeiras e os médicos os seus mentores. Mudanças foram desencadeadas com o ensino da saúde pública/comunitária, a autonomia do ensino começou quando as enfermeiras passaram a intervir no processo da constituição do currículo e, por essa via, adquiriram uma posição central na aprendizagem. A integração no Ensino Superior Politécnico, com a formação de bachareis em Enfermagem, a criação de licenciaturas e a agregação de várias escolas às universidades, sedimentou uma nova etapa da profissão em Portugal.

A criação da Ordem dos Enfermeiros foi o contributo decisivo para o desenvolvimento do ensino e da prática de Enfermagem, já no final do século XX, quando em 1999, finalmente, houve a criação das licenciaturas em Enfermagem e agregação de várias Escolas às Universidades.

\section{REFERÊNCIAS}

1. Nóvoa A. Le Temps des Professeurs. Analyse sociohistorique de la profession enseignante au Portugal (XVIII-XIX siécles). Lisboa: Instituto Nacional de Investigação Científica, 1987.

2. Graça L, Henriques AI. Evolução da prática e do ensino de enfermagem em Portugal. Lisboa: Universidade Nova de Lisboa, Escola Nacional de Saúde Pública, Textos sobre Saúde e Trabalho; 1999. p. 62-78.

3. Oliveira Marques A. História de Portugal. $2^{\mathrm{a}}$ ed. Lisboa: Palas; 1976.

4. Soares MI. Da blusa de brim à touca branca contributos para a história da enfermagem em Portugal (1880-1950). Lisboa: EDUCA, APE; 1997.

5. Nunes L. Um olhar sobre o ombro - enfermagem em Portugal (1881-1998). Loures: Lusociência; 2003.

6. Ferreira C. Administração da saúde em Portugal apontamentos para análise. Rev Port Saúde Publ. 1986 Jan/Jun;1 e 2:135-58.

7. Nogueira MA. História da enfermagem. $2^{\mathrm{a}}$ ed. Porto: Salesianas; 1990.

8. Ferreira FA. História da saúde e dos serviços de saúde em Portugal. Lisboa: Fundação Calouste Gulbenkian; 1990.

9. Decreto-Lei n. 31913 de 12 de março de 1942. Dispõe sobre a proibição do casamento para as enfermeiras e 
dá outras providências. Diário da República de Portugal, I Série, Lisboa. 12 de março 1942.

10. Decreto-Lei n. 32602 de 31 de dezembro de 1942. Regulamenta o ensino da prática de enfermagem. Diário da República de Portugal, I Série, Lisboa. 31 de dezembro 1942.

11. Decreto-lei n. 38884 de 28 de agosto de 1952. Regulamenta a reforma do ensino de enfermagem. Diário da República de Portugal, I Série, Lisboa. 28 de agosto de 1952.

12. Decreto-lei n. 480 de 23 de dezembro de 1988. Regulamenta a integração do curso de enfermagem no sistema educativo superior politécnico. Diário da República de Portugal, I Série, Lisboa. 23 de dezembro 1988.

13. Decreto-Lei n. 166 de 5 de agosto de 1992. Define o regime aplicável ao pessoal docente das escolas superiores de enfermagem. Diário da República de Portugal, I Série, Lisboa. 5 de Agosto de 1992.

14. Decreto-lei n. 104 de 21 de abril de 1998. Criação da Ordem dos Enfermeiros. Diário da República de Portugal I Série, Lisboa. 21 de abril de 1998.

15. Decreto-lei n. 353/99 de 3 de setembro. Confere o grau de licenciatura ao curso de enfermagem. Diário da República de Portugal, I Série, Lisboa. 3 de setembro de 1999. 